\title{
Failure Mechanism of Two-Phase Syntactic Foam Polymer Composites under Different Coating Conditions
}

\author{
LO Afolabi ${ }^{1}, Z^{2}$ Ariff $^{1 *}$, NA AbdulMutalib ${ }^{1}$ \\ School of Materials and Mineral Resources Engineering, Universiti Sains Malaysia, \\ Nibong Tebal, Pulau Pinang, 14300, MALAYSIA \\ *Corresponding Author
}

DOI: https://doi.org/10.30880/ijie.2019.11.07.015

Received 09 October 2019; Accepted 25 October 2019; Available online 15 November 2019

\begin{abstract}
In this study, the impact of coated hollow microsphere (HMs) on syntactic foams (SFs) failure analysis is performed. The HMs was made from polystyrene beads and were coated with $\mathrm{CaCO}_{3}$ and cementite powder to produce the SFs by Vacuum Assisted Mould Fill Technique (VAMFT). The morphological analysis was performed using Scanning Electron Microscope (SEM) and the compressive test conducted using INSTRON 5982 machine model. From the results, the HMs failure mechanism showed the cementite surface coating enhanced the shellrigidity by $65 \%$. The physical and compressive properties of the SFs increased with increase in $\%$ vol. fraction of the HMs. The SFs compressive modulus, flexural strength and tensile strength for the $\mathrm{CaCO}_{3}$ and cementite specimen are 470, 44, $36 \mathrm{MPa}$ and 582, 48, $41 \mathrm{MPa}$, respectively. The energy absorption characteristic of the SFs was enhanced by $14 \%$ and $25 \%$ for the $\mathrm{CaCO}_{3}$ and cementite HMs surface coating, respectively. But the optimal concentration for the SFs was $20 \%$ vol. weight for both HMs coating.
\end{abstract}

Keywords: Hollow microspheres, compressive stress, flexural stress, syntactic foam, and mechanical properties

\section{Introduction}

Here small spherical particles with diameter in the micrometer range (typically 1 to $1000 \mu \mathrm{m}$ ) are commonly referred to as microspheres. And in some cases, micro-particles [1-3]. Microspheres can be fabricated from different types of natural and synthetic materials or even inorganic materials. Cases of fabrication of microspheres from commercially available ceramics microspheres, glass microsphere, or polymers microsphere have been reported in literatures [2, 4-6]. Depending on the technique, solid or hollow microspheres are widely used in density and, therefore, are used for different or specific intended applications [7-9]. Hollow microspheres (HMs) offers superior properties and diverse range of application in engineering technology. And are typically used as additives to lower the density of material. There are numerous applications of microspheres depending on what material they are produced from and what size they are and there usage spawn across aerospace, marine underwater vessels, ground vehicles etc. The two very common types of polymeric microspheres are the polyethylene and polystyrene. Polystyrene microspheres present a flexible platform for applications and can be coated to enhance the shell-wall properties. Hollow microsphere from polystyrene have been studied widely for fabrication of syntactic foams (SFs) because of the advantage properties [10].

Studies on incorporation of microspheres into matrices to produce lightweight material (foams) have been reported in literatures [7, 11-13]. Composite materials produced by embedding porous particles in a matrix medium can be referred to SFs. Researchers studied SFs because of the low density, superior compressive strength, acoustic, thermal damping and electromechanical properties [14-16]. SFs have been used for buoyancy in subsurface and deep-sea applications, sandwich structures for aerospace, aviation and transportation, thermal insulation materials for oil and gas industries and other applications [17-23]. Also, matrix types, matrix formulation and SFs performance have been studied widely [24-26], while filler types [26-30], porous microsphere types [22, 31-33] and method of production [30, 
34, 35]. SFs compressive properties, modulus elasticity, flexural strength, tensile strength, thermo-insulation, thermochemical and sound properties have been enhanced by manipulating various factors [36-38]. Although, there have been considerable progress achieved in the study of SFs application [18, 39, 40]. But there are few research endevoiur on the types and effect of microsphere surface coatings on the SFs [41]. Surface coating of microsphere considerable influence SFs performance [40, 42, 43]. However, more investigation on suitable coating materials surface coating types, coating size, coating thickness, coating treatment, coating homogenousity and methods for the microsphere used inn fabrication of SFs in order to improve thermomechanical, sound acoustic and insulation properties. In view of the shortage in literature this study evaluates the effects of surface coating on SFs incorporated microsphere for acoustical applications.

\section{Material and characterization}

\subsection{List of materials}

All Expandable polystyrene beads and epoxy resin based diglycidyl ether of Bisphenol and epoxy hardener clear was purchased from Euro Chemo Pharma Sdn, Bhd, Pinang, Malaysia. The equivalent weight of the epoxy resin weight is $188 \mathrm{~g} / \mathrm{eq}$, and physical properties: viscosity $13456 \mathrm{mPa} / \mathrm{s}$; density $1.16 \mathrm{~g} / \mathrm{ml}$; and weight $9.7 \mathrm{lbs}$. /gal). The chemical composition proportion is 5-11 Trimethylhexamethylene diamine (TMD), 30-42 Isophorone diamine, 29-41 benzyl alcohol. And the equivalent weight per $\mathrm{H}$ active is $95 \mathrm{~g} / \mathrm{eq}$, Amine value $278 \mathrm{mg} \mathrm{KOH} / \mathrm{g}$, viscosity 36 , density $1.0 \mathrm{~g} / \mathrm{ml}$ and gel time at $25^{\circ} \mathrm{C}$ is 32 mins at ration $1: 1$.

\subsection{Fabrication coated microsphere and matrix formulation}

The stoichiometry ratio used for the matrices was 1:1 epoxy resin clear and epoxy hardener clear. The expandable polystyrene beads size ranges between 1-5 $\mathrm{mm}$. The epoxy resin was poured inside aluminium bowl, and polystyrene beads were added at apportioned quantity into it and mixed thoroughly till the outer surface of the beads are fully wetted. Thereafter, the wetted beads were poured onto a tray of dried $\mathrm{CaCO}_{3}$ powder to form shell coating. The excess powders were removed from the bead to prevent agglomerating. The coated beads were cured inside oven at $60^{\circ} \mathrm{C}$ for 30 minutes. Similar procedure was repeated for the cementite powder coatings.

\subsection{Fabrication of microsphere}

Post curing of the coated beads was done by putting the coated beads inside oven for another 90 mins at $120^{\circ} \mathrm{C}$ to allow the shrinking process of the beads - creating intended inner hollow structure. Thereafter, the resultant cured coated beads - hollow microsphere (HM) were sieved to remove excess coatings on their surface. Table 1 presents the physical properties of the microsphere studied.

Table 1- Physical properties of microsphere

\begin{tabular}{|c|c|c|c|c|c|}
\hline $\begin{array}{l}\text { Types of } \\
\text { microsphere } \\
\text { /surface coating }\end{array}$ & $\begin{array}{l}\text { Density } \\
\left(\mathrm{kg} / \mathrm{m}^{3}\right)\end{array}$ & $\begin{array}{c}\text { Exa } \\
\text { Pressure } \\
\text { (MPa) }\end{array}$ & $\begin{array}{l}\text { Average } \\
\text { diamet } \\
\text { er }\end{array}$ & $\begin{array}{c}\text { Average } \\
\text { thickne } \\
\text { ss }\end{array}$ & $\begin{array}{l}\text { Thickness } \\
\text { to- } \\
\text { radius- }\end{array}$ \\
\hline $\begin{array}{l}\text { Calcium } \\
\text { carbonate coated }\end{array}$ & 0.6431 & $\begin{array}{l}3 . \\
67\end{array}$ & 1.8 & $\begin{array}{l}1 . \\
15\end{array}$ & 0.042 \\
\hline $\begin{array}{l}\text { Cementite coated } \\
\text { microspheres }\end{array}$ & 0.7234 & 4.12 & 2.0 & 1.23 & 0.038 \\
\hline
\end{tabular}

\subsection{Fabrication syntactic form}

The SFs was produced using epoxy resin as binder and hollow microsphere as fillers. The fabrication was done by Vacuum Assisted Mould Filled Techniques (VAMFT). Teflon mould was filled up with cured HMs. Then after, the matrix mixture was gradually poured into the mould and simultaneously expelling the air inside the mould by vacuuming. The mould was air tight with silicon grease. Natural curing of the SFs occurred through 5 days, before the mould was opened and the SFs exposed. Figure 1 shows the photo-image of the cut-size SFs and the cured coated HMs.

\subsection{Microstructure Analysis}

Morphology of the epoxy HMs was viewed by Hitachi S-3000 N SEM imaging. The imaging captures the morphological alignment of the HMs in the SFs. Several images of the SFs were captured with varying magnifications and sizes, however, only the discussion was mainly focused on one magnification and concentration of HMs. 



Fig. 1- Photo-image of different hollow microsphere (HMs) surface coating and Syntactic foams (SFs) (a) $\mathrm{CaCO}_{3}$ coated HMs; (b) Cementite coated HMs; (c) SFs with $\mathrm{CaCO}_{3} \mathrm{HMs}$; (d) SFs with Cementite HMs

\subsection{Compression test}

ASTM D3575 standard was adopted for the compression test. The specimen dimension is $50 \times 50 \times 25 \mathrm{~mm}$. The test was conducted in triplicate every batch of the epoxy SFs for accuracy of results. The test was conducted at room temperature using a universal testing machine model INSTRON 5982 at constant cross-head speed of $5 \mathrm{~mm} / \mathrm{mins}$ at $60 \%$ strain between two parallel flat plates.

\section{Result and discussion}

\subsection{Microsphere and crushing mechanism analysis}

The compressive stress - strain curve is shown in Figure 2. The Matrix formulation is known to impact the macromolecular structure of the microspheres thus influencing the microspheres performance [40, 44].

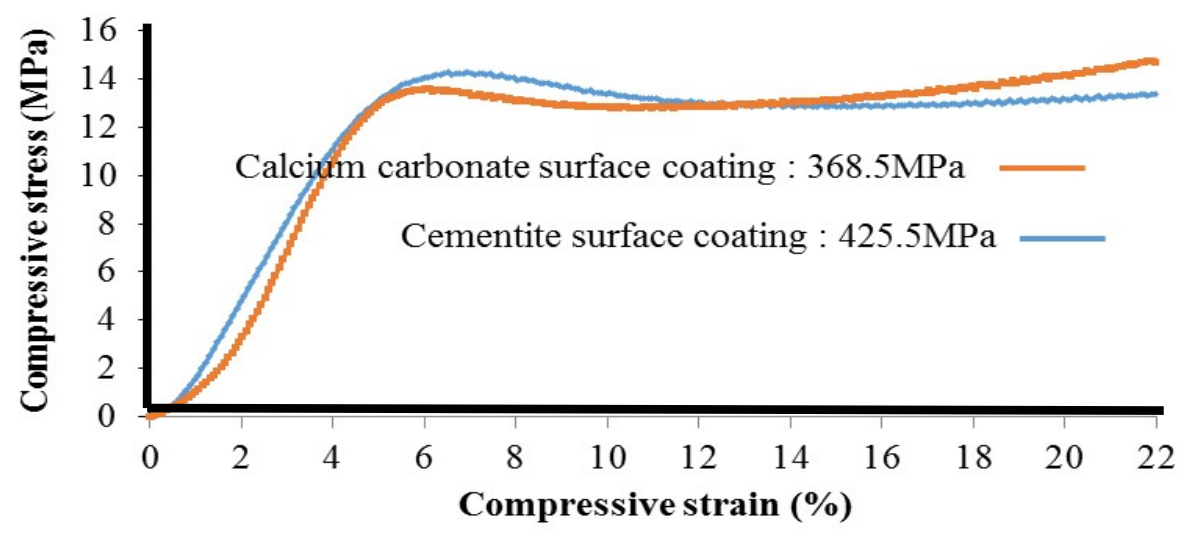

Fig. 2 - Stress-strain curve for hollow microsphere with different surfaces coating: (a) Calcium carbonate coating and (b) Cementite coatings 
Analysis of crushing mechanism on HMs shows resistance towards compression load because both the matrix and HMs strength was combined in yielding the foam's compressive deformation response. The coated HMs with cementite exhibited higher compressive modulus (425.5 MPa) than the epoxy HMs coated with CaCO3 (368.5 MPa). Their curves pattern is linear-elastic which is hypothetical of stress-strain curve analysis. Characteristic behavior of the epoxy HMs for both coating surfaces under compressive testing was visualized using the Stereo Zoom microscope.

Figure 3 and 4 describes the fracture propagation of the $\mathrm{CaCO} 3$ and cementite coated $\mathrm{HMs}$, respectively. The failure propagation stages of the microsphere is captured on image camera and presented in Figure 3 . The arrow shows the captured images as the crush is been impacted. The microsphere crushing strength impacts the compressive strength of foam. However, have less contribution when in the deformation was in flexural mode, [19, 45-47]. For example, in a resin rich matrix, the excess number of epoxy resin monomer that is unreactive avoids a complete crosslink thereby causing a weak polymer structure formation.

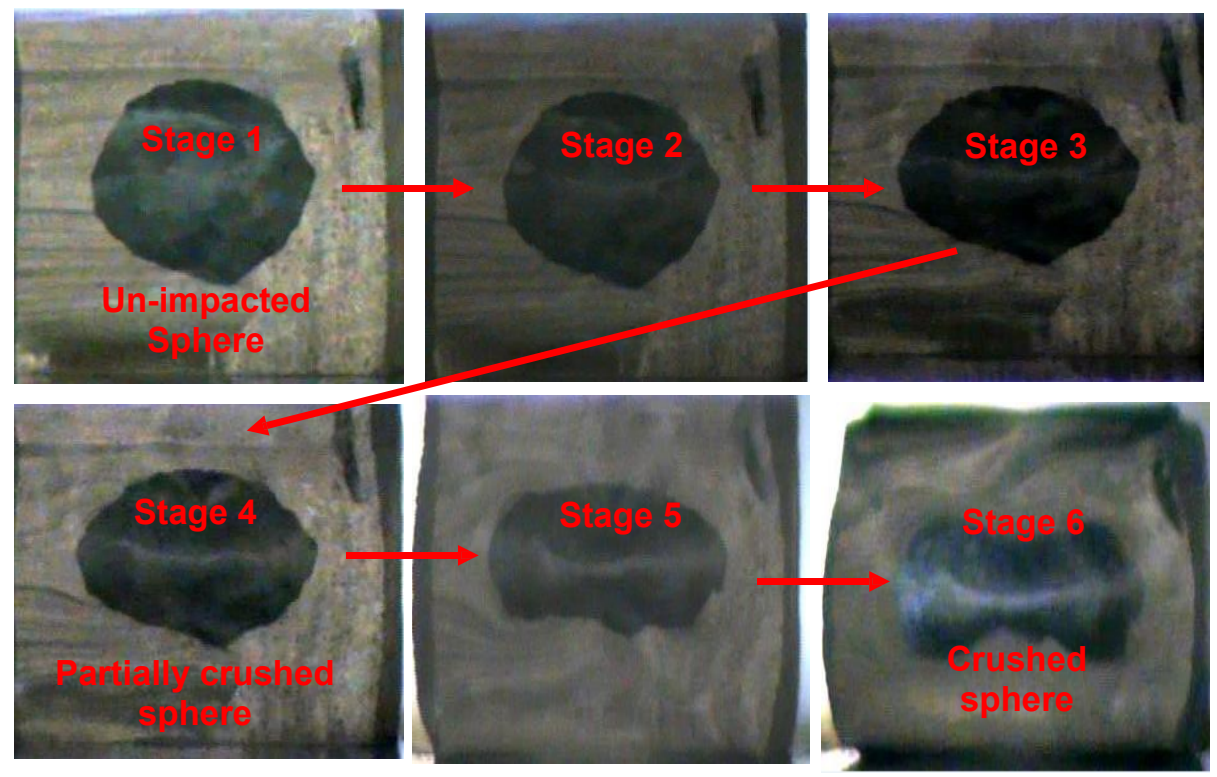

Fig. 3 - Failure propagation image captured during compression testing of $\mathrm{CaCO} 3$ coated HMs

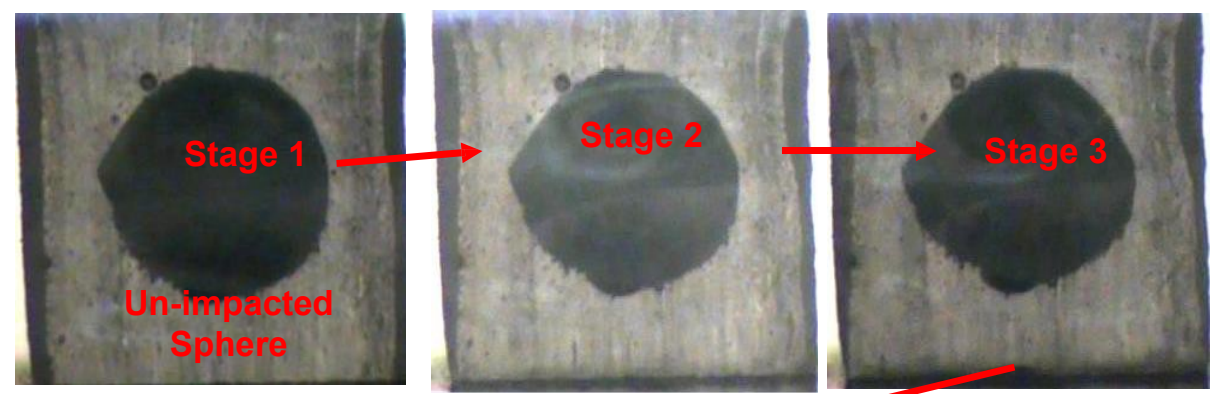

(d)

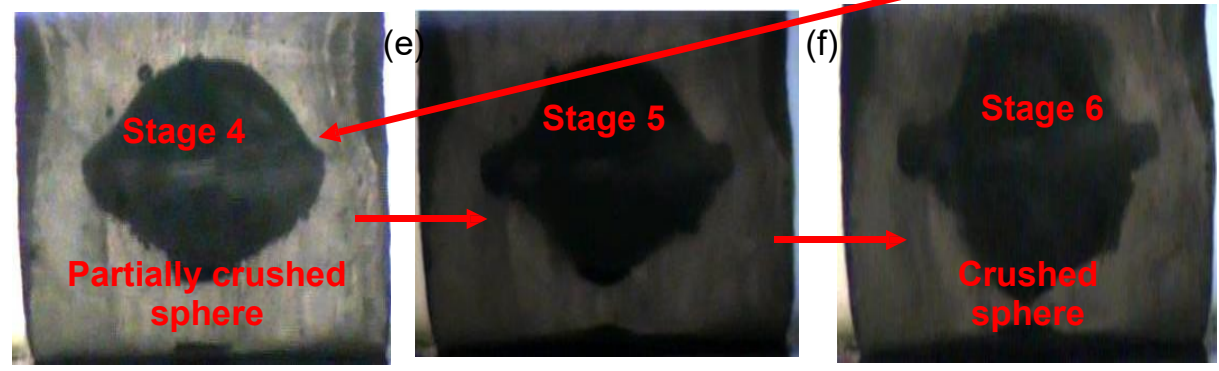

Fig. 4 - Failure propagation Image captured during compression testing of Cementite coated HMs

At weak structure of epoxy resin, cracks initiates throughout the system and primarily point of cracks occurs at excess epoxy spot identified as voids thus contributes to the low deformation capacity of overall system. The crushing behaviour of the $\mathrm{CaCO}_{3}$ coated HMs was brittle and protrudes during compression. Noticeable crack formation which are failure concentration points are observed as shown in Figure 3. This implies that the surface coating initiated 
minimized crack initiation does enhancing the compressive strength of the epoxy HMs. The Figure 4 presents the capture images showing the failure mechanics for the cementite coated surface microsphere. The cementite coating coated HMs was more effective and unbroken because of the presence of substantial number of active amine group which exhibit stronger shell, structural rigidity and stronger interfacial bond between HMs and epoxy matrix. Whereas, the $\mathrm{CaCO}_{3}$ coated epoxy HMs, the surface exhibited brittleness because of formation of rigid macromolecular structure. During compressive testing, the HMs cracked and creates void which leads to stress concentration points. Overall compressive strength rely on contribution strength of the individual HMs. Microspheres of averagely even sizes, and coated surfaces can contribute to elongation of the sphere.

Figure 5 and 6 describes the failure propagation under compressive test for both coated surfaces using the edgewise and flatwise orientation. From Figure 5, It can be observed that the edgewise compression is more impacted upon than the flatwise orientation for the calcium carbonate coated HMs. The modulus for the flatwise and edgewise was $42 \mathrm{MPa}$ and $26 \mathrm{MPa}$, respectively.



Fig. 5 - Stress-strain curve for calcium carbonate coated HMs under different failure propagation orientation

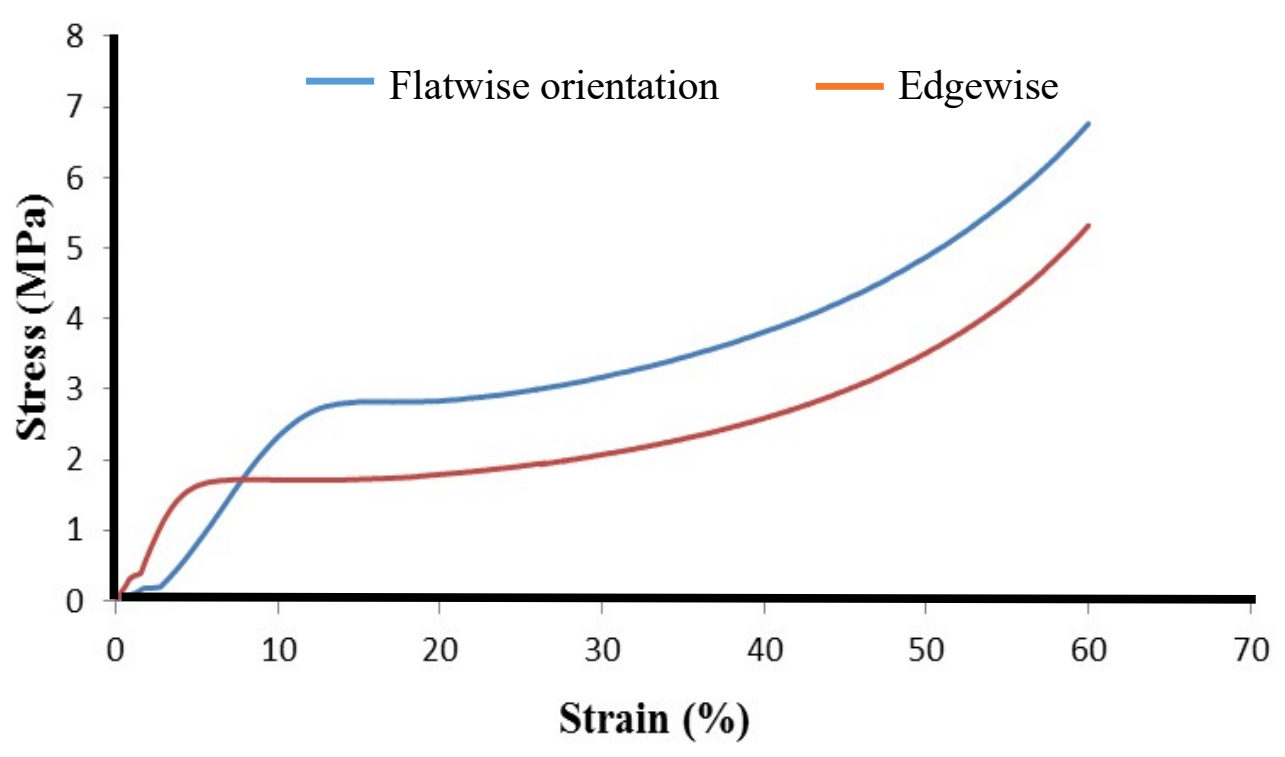

Fig. 6 - Stress-strain curve for cementite coated HMs under different failure propagation orientation

From Figure 6 the cementite coated HMs, the modulus for the edgewise and flatwise was $46 \mathrm{MPa}$ and $29 \mathrm{MPa}$, respectively. The difference in their modulus can be traced to the barrier the coating provided to the HMs. whereas the cementite coated surface with relatively higher modulus from both failure propagation orientation is because of the yield elasticity provided to the microsphere shell. 


\subsection{Syntactic foams (SFs)}

Figure 7 describe the SFs compressive curve. The position of the curves exhibits identical cross-linking because of the microspheres. However, the slight variation can be traced to the coating effects. The coated SFs compressive modulus was enhanced by $45 \%$ compared to the uncoated epoxy SFs. Similar findings have been reported in the works of many researchers $[46,47]$. Thus implies that the mechanical properties of SFs had obvious enhancement by adding external surface coatings to the microspheres and the matrix. However, the ESF coated with cementite showed higher modulus $(582 \mathrm{MPa})$ than the epoxy SFs coated calcium carbonate with modulus $(470 \mathrm{MPa})$. This can be traced to the effect of the surface coating material. The two coating have identical microsphere size and thickness.

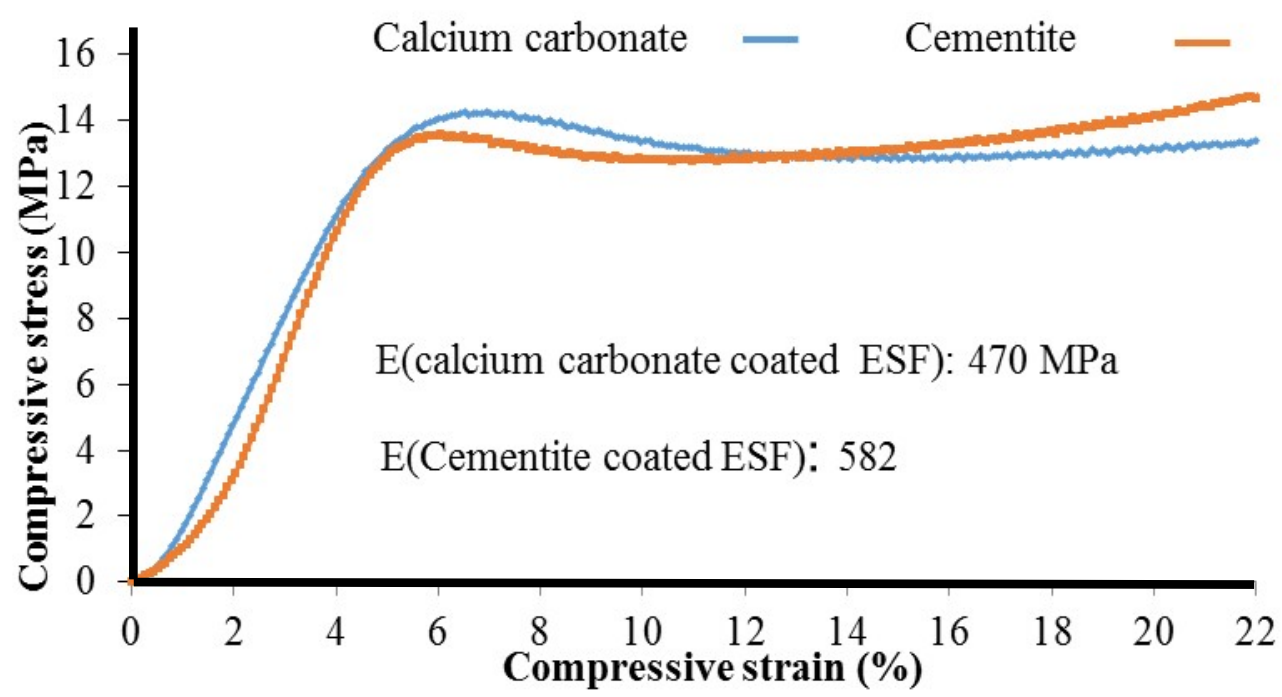

Fig. 7 Compressive Stress-strain curve comparison of calcium carbonate coated SFs and cementite coated SFs

Table 2 shows the specific tensile strength and specific flexural strength against percentage volume concentration. Literature reports shows that the flexural strength, tensile strength and elastic modulus are enhanced by the filler [48, 49]. In the case of the calcium carbonate shell coating, the specific tensile strength increases and the specific flexural strength decreases with increase in volume percentage (\%) of the epoxy HMs. Whereas, in the case of the cementite shell coating, the specific tensile strength increased and specific flexural strength decrease with increase in the epoxy HMs volume percentage (\%). For both shell coatings at $20 \%$ volume concentration of epoxy HMs demonstrated the highest specific tensile strength of $44 \mathrm{MPa}$ and $48 \mathrm{MPa}$ for calcium carbonate and cementite epoxy SFs respectively. Whilst the lowest specific flexural strength was recorded at $50 \%$ volume percentage of epoxy HMS for both shell coating on the epoxy SFs.

Table 2 - Comparison of the compressive strength properties of SFs against weight volume (\%)

\begin{tabular}{lccc}
\hline $\begin{array}{l}\text { Epoxy } \\
\text { Syntactic Foam }\end{array}$ & $\begin{array}{l}\text { Specific Tensile } \\
\text { Strength } \\
\text { Shell Coatings }\end{array}$ & $\begin{array}{l}\text { Specific } \\
\text { Flexural } \\
\text { Strength }\end{array}$ & $\begin{array}{c}\text { Epoxy } \\
\text { Hollow } \\
\text { Microsphe }\end{array}$ \\
\hline & 2 & 7 & 10 \\
Calcium carhnnate & 4 & 5 & 20 \\
& 3 & 4 & 30 \\
& 3 & 4 & 40 \\
& 3 & 3 & 50 \\
\hline & 2 & 6 & 10 \\
& 4 & 6 & 20 \\
& 4 & 5 & 30 \\
& 3 & 5 & 40 \\
& 3 & 4 & 50 \\
\hline
\end{tabular}

However, $41 \%$ and $49 \%$ reduction in the flexural strength property of the epoxy SFs was recorded for the calcium carbonate and cementite shell coating. Thus, external surface coatings can enhance the strength of composite, however, 
the enhancement in the cementite coating was more because of the crosslink formed with the matrix-resin and the increased content of the epoxy HMs. Overall, the epoxy HMs shell coating contributes to enhancement of compressive properties of epoxy SFs. However, the respectful contribution is based on the shell coating material type, coating thickness, and load concentration in the epoxy SFs. The cementite surface coating improved the compressive properties of the epoxy SFs more than the calcium carbonate coating in most retrospect examined.

\subsection{Microstructure Analysis}

Figure 8 presents the SEM images for both the epoxy SFs from calcium carbonate and cementite shell coating surfaces. From Figure 8a, the epoxy HMs are closely-packed with noticeable deformation in the epoxy HMs from the original spherical shape, though in some cases. Also, the particle concentration increases and volume of matrix resin decreases with increasing epoxy HMS loading, though as expected. The microstructure suggests the rigidity and toughness of the coating affect the external surfaces of the epoxy HMs unlike the shape and size that evolves during the composite fabrication process.
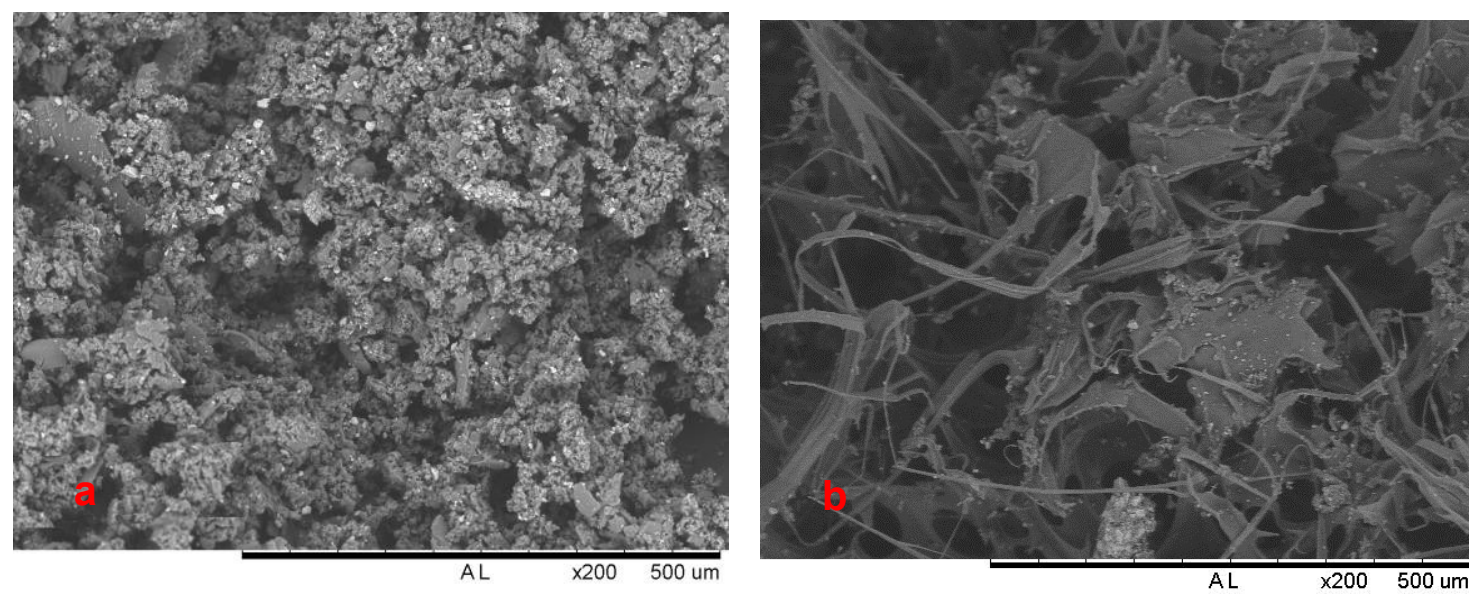

Figure 8: SEM microstructural images for epoxy syntactic foam (SFs).

(a) Calcium carbonated coated surface and (b) Cementite coated surface.

The moduli and fracture properties often improve with increased solid filler content, given an intrinsically brittle matrix system and good interfacial bonding between the filler and the matrix [50, 51]. Herein, both surface coatings provided enhanced interfacial bonding between the matrix and the filler, but the calcium carbonate coated surfaces was much smoother and homogenous than the cementite because of the fine particle size and density. Average of 50 samples of the epoxy HMS were used to determine the density of the syntactic foam.

\section{Conclusion}

The theme of the study focuses on the evaluations of the contribution of different HMs surface coatings on SFs physical and mechanical properties. And the SFs failure mechanism analysis from edgewise and flatwise orientation upon loading systems. The experimental characterization of the HMs and SFs was carried out using scanning electron microscopy (SEM) for the morphology of the SFs and HMs internal structure and the compressive strength was carried out with compression test machine. From the results the HMs wall coating were observe to enhance the structural rigidity, toughness (malleability) and compressive strength of the SFs. However, the cementite wall coating SFs exhibited the high modulus but low density when compared with $\mathrm{CaCO}_{3}$ wall coating SFs and plain SFs. This lightweight SFs can be used in various acoustical and mechanical engineering applications especially where impact assessment and light weight applications are highly required. And where materials are exposed to repetitive compressive and impact events because of the advantageous and tailored properties.

\section{Acknowledgement}

We acknowledge the support of the Technologist at School of Materials and Mineral Resources Engineering, Universiti Sains Malaysia for equipment usage, guidance, and help with experimentation. And also thank Universiti Sains Malaysia for the financial support provided through the Research University (RUI) grant (ref. no.: 1001/PBAHAN/80114041).

\section{References}


[1] Regin, A. F., Solanki, S., Saini, J., (2008). Heat transfer characteristics of thermal energy storage system using PCM capsules: a review: Renewable and Sustainable Energy Reviews, 12, 2438-2458.

[2] Yu, C., Zhou, W., Liu, H., Liu, Y., Dionysiou, D. D. (2016). Design and fabrication of microsphere photocatalysts for environmental purification and energy conversion: Chemical Engineering Journal. 287, 117129.

[3] Kakar, S., Batra, D., Singh, R., Nautiyal, U. (2013). Magnetic microspheres as magical novel drug delivery system: A review, Journal of acute disease. 2, 1-12.

[4] Rum, R. H. M. (2019). Density and Strength of Foamed Concrete: The Influence on Dynamic Characteristics of Lightweight Profiled Composite Slabs. International Journal of Integrated Engineering, 11, 285-295.

[5] Gupta, V., Khan, Y., Berkland, C. J., Laurencin, C. T., Detamore, M.S. (2017). Microsphere-based scaffolds in regenerative engineering. Annual review of biomedical engineering, 19, 135-161.

[6] Afolabi, L. O., Mutalib, N. A. A., Ariff, Z. M. (2019). Fabrication and characterization of two-phase syntactic foam using vacuum assisted mould filling technique. Journal of Materials Research and Technology, 8, 3843 3851 .

[7] Joshi, N., da Silva, L. F., Jadhav, H. S., Shimizu, F. M., Suman, P. H., M'Peko, J. C. (2018). Yolk-shelled $\mathrm{ZnCo}_{2} \mathrm{O}_{4}$ microspheres: Surface properties and gas sensing application," Sensors and Actuators B: Chemical, 257, 906-915.

[8] Zhang, L., Chen, Y., Hu, X., Liu, M. (2015). Nanofiller reinforcement versus surface treatment effect on the mechanical properties of syntactic foams. International Conference on Experimental Mechanics, 2015, 93(21).

[9] Radzuan, N. A. M., Sulong, A. B., Mamat, M. R., Tharazi, I., Tholibon, D., Dweiri, R., et al., 2018. "Kenaf Reinforced PLA Composite Thermoforming: A Numerical Simulation," International Journal of Integrated Engineering, 10, 234-237.

[10] Ng, C. H., Yahaya, S. N. M., Lai, C. F., Sharrifuddin, F., and Grote, K. H. 2018 "Reviews on the Forming Process of Heat Treatable Aluminium Alloys," International Journal of Integrated Engineering, 10, 167-170. [11] Ko, Y. N., Choi, S. H., Kang, Y. C. (2016). Hollow cobalt selenide microspheres: synthesis and application as anode materials for Na-ion batteries. ACS applied materials \& interfaces, 8, 6449-6456.

[12] Naing, N. N., Li, S. F. Y., Lee, H. K. (2016). Application of porous membrane-protected chitosan microspheres to determine benzene, toluene, ethylbenzene, xylenes and styrene in water. Journal of Chromatography A, 1448, 42-48.

[13] Ding, G. J., Zhu, Y. J., Qi, C., Lu, B. Q., Chen, F., Wu, J. (2015). Porous hollow microspheres of amorphous calcium phosphate: soybean lecithin templated microwave-assisted hydrothermal synthesis and application in drug delivery. Journal of Materials Chemistry B, 3, 1823-1830.

[14] Geng, H., Liu, J., Guo, A., Ren, S., Xu, X., Liu, S. (2016). Fabrication of heat-resistant syntactic foams through binding hollow glass microspheres with phosphate adhesive. Materials \& Design, 95, 32-38.

[15] Smith, Z. D., Keller, J. R., Bello, M., Cordes, N. L., Welch, C. F., Torres, J. A. (2016). P lackett-B urman experimental design to facilitate syntactic foam development. Journal of Applied Polymer Science, 133, 2016.

[16] Pinisetty, D., Shunmugasamy, V. C., Gupta, N. (2015). Hollow glass microspheres in thermosets-epoxy syntactic foams in Hollow Glass Microspheres for Plastics, Elastomers, and Adhesives Compounds, ed: Elsevier, 147-174.

[17] Gupta, N., Zeltmann, S. E., Shunmugasamy, V. C., Pinisetty, D. (2014). Applications of polymer matrix syntactic foams. 66, 245-254.

[18] Ozkutlu, M., Dilek, C., Bayram, G. (2018). Effects of hollow glass microsphere density and surface modification on the mechanical and thermal properties of poly (methyl methacrylate) syntactic foams. Composite Structures, 202, 545-550.

[19] Ghosh, D., Wiest, A., Conner, R. D. (2016). Uniaxial quasistatic and dynamic compressive response of foams made from hollow glass microspheres. Journal of the European Ceramic Society, 36,781-789.

[20] Sankaran, S., Ravishankar, B., Sekhar, K. R., Dasgupta, S., Kumar, M. J. (2017). Syntactic foams for multifunctional applications," in Composite Materials, ed: Springer, 281-314.

[21] Luong, D. D., Ansuini, L., Gupta, N. (2018). Dynamic Response of Syntactic Foams and Sandwich Composites: Blast and High Strain Rate Loading," in Blast Mitigation Strategies in Marine Composite and Sandwich Structures, ed: Springer, 171-190.

[22] Bharath Kumar, B. R., Doddamani, M., Zeltmann, S. E., Gupta, N., Ramesh, M. R., Ramakrishna, S. (2016). Processing of cenosphere/HDPE syntactic foams using an industrial scale polymer injection molding machine," Materials \& Design, 92, 414-423.

[23] Kumar, B. B., Doddamani, M., Zeltmann, S. E., Gupta, N., Ramesh, M., Ramakrishna, S. (2016). Processing of cenosphere/HDPE syntactic foams using an industrial scale polymer injection molding machine. Materials \& Design, 92, 414-423. 
[24] Zeltmann, S., Chen, B., Gupta, N. (2017). Mechanical properties of epoxy matrix-borosilicate glass hollowparticle syntactic foams. Materials Performance and Characterization, 6, 1-16.

[25] Zeltmann, S. E., Chen, B., Gupta, N. (2018). Thermal expansion and dynamic mechanical analysis of epoxy matrix-borosilicate glass hollow particle syntactic foams. Journal of Cellular Plastics, 54, 463-481.

[26] Zeltmann, S. E., Gupta, N., Chen, B., Ricci, W. (2015). Mechanical properties of borosilicate glass hollow particle reinforced epoxy matrix syntactic foams. Baltimore 2015 Conference and Exhibition.

[27] Pan, 1., Yang, y., Ahsan, M. U., Luong, D. D., Gupta, N., Kumar, A. (2018). Zn-matrix syntactic foams: Effect of heat treatment on microstructure and compressive properties," Materials Science and Engineering: A, 731, 413-422.

[28] Yang, Q. Z., Wei, Y. P., Miao, Z. Q., Gao, P., Yu, B. (2018). The Processing and Structure of Steel Matrix Syntactic Foams Prepared by Infiltration Casting. Materials Science Forum, 129-135.

[29] Licitra, L., Luong, D. D., Strbik III, O. M., Gupta, N. (2015). Dynamic properties of alumina hollow particle filled aluminum alloy A356 matrix syntactic foams. Materials \& Design, 66, 504-515.

[30] Kang, Y., Lee, W., Hwang, J., Lee, Y. (2018). Influence of Glass Microsphere Filler on the Rheological Behavior of an Epoxy Resin. International Polymer Processing, 33, 146-152.

[31] Szlancsik, A., Katona, B., Májlinger, K., Orbulov, I. N. (2015). Compressive behavior and microstructural characteristics of iron hollow sphere filled aluminum matrix syntactic foams, Materials, 8, 7926-7937.

[32] Bálint, A., Szlancsik, A. (2015). Mechanical Properties of Iron Hollow Sphere Reinforced Metal Matrix Syntactic Foams, Materials Science Forum, 3-8.

[33] Szlancsik, A., Katona, B., Károly, D., Orbulov, I. N. (2019). Notch (In) Sensitivity of Aluminum Matrix Syntactic Foams," Materials, 12, 574.

[34] Spratt, M., Newkirk, J., Chandrashekhara, K. (2017). Aluminum Matrix Syntactic Foam Fabricated with Additive Manufacturing, 234, 321-324.

[35] Zhou, J., Zhao, H., Wang, J., Qiao, W., Long, D., Ling, L. (2016). Scalable preparation of hollow polymer and carbon microspheres by spray drying and their application in low-density syntactic foam," Materials Chemistry and Physics, 181, 150-158.

[36] Sherman A. J., Doud, B. (2018). Syntactic metal matrix materials and methods," ed: Google Patents.

[37] Papantoniou, I., Markopoulos, A., Pantelis, D., Manolakos, D. (2018). Application of Aluminium Flakes in Fabrication of Open-Cell Aluminium Foams by Space Holder Method," Materials, 11, 1420.

[38] Singh, A. K., Shishkin, A., Koppel, T., Gupta, N. (2018). A review of porous lightweight composite materials for electromagnetic interference shielding," Composites Part B: Engineering, 149, 188-197.

[39] Khatavkar, N., Balasubramanian, K. (2016). Composite materials for supersonic aircraft radomes with ameliorated radio frequency transmission-a review," RSC Advances, 6, 6709-6718.

[40] Ryzhenkov, A. V., Pogorelov, S. I., Loginova, N. A., Belyaeva, E. V., Plestsheva, A. Y.(2015). Syntactic Foams Efficiency with the Use of Various Microspheres for Heat Supply Equipment and Pipelines Heat Insulation," Modern Applied Science, 9, 319.

[41] Ranjbar, N., Kuenzel, C. (2017). Cenospheres: A review, Fuel, 207, 1-12.

[42] Mao, S., Xu, J., Cai, C., Germershaus, O., Schaper, A., Kissel, T. (2007). Effect of WOW process parameters on morphology and burst release of FITC-dextran loaded PLGA microspheres, International journal of pharmaceutics, 334, 137-148.

[43] Keerio, M. A., Lakhiar, M. T., Sohu, S. (2019). Comparative Study on Flexural Performance of Foamed Concrete Beam Containing Plastic Fibres, International Journal of Sustainable Construction Engineering and Technology, 10, 12-16.

44] Rahman, A. F., Goh, W., Jhatial, A. (2019). Flexural Study of Reinforced Foamed Concrete Beam Containing Palm Oil Fuel Ash (POFA) and Eggshell Powder (ESP) as Partial Cement Replacement, International Journal of Sustainable Construction Engineering and Technology, 10, 14-18.

[45] Koopman, M., Chawla, K., Carlisle, K., Gladysz, G. (2006). Microstructural failure modes in three-phase glass syntactic foams, Journal of Materials Science, 41, 4009-4014.

[46] Rohatgi, P. K., Gupta, N., Schultz, B. F., Luong, D. D. (2011). The synthesis, compressive properties, and applications of metal matrix syntactic foams, Jom, 63, 36-42.

[47] Smorygo, O., Mikutski, V., Marukovich, A., Sadykov, V., Bespalko, Y., Stefan, A. (2018). Preparation and characterization of open-cell epoxy foams modified with carbon fibers and aluminum powder, Composite Structures, 202, 917-923.

[48] Yu, W., Xue, H., Qian, M. (2017). Tensile and compressive properties of epoxy syntactic foams reinforced by short glass fiber, 113, 32-36.

[49] Zhi. C., Long, H. (2016). Flexural Properties of Syntactic foam Reinforced by Warp Knitted Spacer Fabric, Autex Research Journal, 16, 57-66.

[50] Wouterson, E. M., Boey, F. Y., Hu, X., Wong, S. C. (2005). Specific properties and fracture toughness of syntactic foam: Effect of foam microstructures, Composites Science and Technology, vol. 65, pp. 1840-1850. 
[51] Basmanav, F. B., Kose, G. T., Hasirci, V (2008). Sequential growth factor delivery from complexed microspheres for bone tissue engineering, Biomaterials, 29, 4195-4204. 